\title{
Narrow band imaging endoscopy for real-time assessment of duodenal villi
}

\author{
Amit Kumar Dutta
}

Received: 13 June 2014 / Accepted: 14 June 2014 / Published online: 8 July 2014

(C) Indian Society of Gastroenterology 2014

The technology of narrow band imaging (NBI) has been available commercially for about a decade. The NBI filter allows only blue and green wavelength of light to pass through and this gives blood vessels a dark appearance [1]. This, along with image magnification and the use of a high definition monitor, allows detailed assessment of the microsurface and microvascularity of the mucosal surface. Accordingly, the information obtained during NBI endoscopy is much more than during conventional white light endoscopy [2]. In the duodenum, villi are clearly seen during magnification NBI endoscopy. Most studies on NBI in the gastrointestinal tract have focussed on the esophagus and colon especially for the evaluation of Barrett's esophagus and detection of colorectal polyps [3, 4]. In contrast, relatively little data is available on its utility in assessing duodenal pathology. This technology has been reported to be helpful in assessing ampullary lesions and detecting villous atrophy in the duodenum [5-8].

The study by Goswami et al. published in the current issue of this Journal [9] assesses the role of NBI in predicting duodenal villous morphology. They prospectively enrolled 105 patients with suspected malabsorption and compared the observations made on duodenal villous morphology during NBI endoscopy with histopathology findings. Interestingly, 59 patients had celiac disease or tropical malabsorption and only 1 patient had irritable bowel syndrome (IBS). As chronic diarrhea was one of the inclusion criteria, one would have expected more IBS patients in the study population. Fiftyeight patients had villous atrophy on histology and magnification NBI imaging had $95 \%$ sensitivity and $90.2 \%$ specificity in detecting villous atrophy when interpreted by the

\footnotetext{
A. K. Dutta $(\bowtie)$

Department of Gastroenterology, Christian Medical College,

Vellore 632 004, India

e-mail: akdutta1995@yahoo.co.in
}

person performing the procedure. The endoscopy images were also assessed by another person and they found good interobserver agreement with the primary assessor. The authors have classified the appearance of duodenal villi on magnification NBI into four categories, although this lacked external validation as the authors have mentioned. The appearance of duodenum on NBI endoscopy in patients with normal villi, partially atrophic villi, and completely atrophic villi has been already described in previous studies, and the current study does not provide any additional features for observation $[6,7]$. However, results from this study are a welcome addition to the data on the usefulness of NBI in duodenal disease.

The findings from this study are encouraging and indicate that NBI has a potential role in detecting villous atrophy. A few previously published studies have shown similar results $[6,7,10]$. Table 1 shows the results of these studies along with data from the current study. All of them show very good sensitivity and specificity of magnification NBI in detecting duodenal villous atrophy. Normal duodenal villi appear finger or leaf-shaped while abnormal villi appear short and stubbed or gyrate or are completely absent. In a clinical setting, this would potentially help targeting biopsies to abnormal appearing areas to improve diagnostic yield compared to random biopsy. This may be especially relevant in patients with positive celiac serology and normal previous duodenal biopsy as NBI can detect the presence of patchy atrophy which is sometimes seen in patients with celiac disease [10, 11]. It might also help to reduce the need for biopsy if villi appear normal and thus reduce the cost of care.

Having discussed the potential benefits, we need to exercise some caution before reaching firm conclusions. All causes of malabsorption may not be associated with villous atrophy and hence duodenal biopsy may still be required in cases of suspected malabsorption. The cost of the equipment, added cost of the procedure to the patient for using NBI endoscopy, increased procedure time, and need for sedation 
Table 1 Performance of narrow band imaging endoscopy in assessing duodenal villous atrophy

\begin{tabular}{|c|c|c|c|}
\hline \multirow[t]{2}{*}{ Authors } & \multirow[t]{2}{*}{ Setting } & \multicolumn{2}{|c|}{ Detection of duodenal villous atrophy on narrow band imaging endoscopy } \\
\hline & & Sensitivity & Specificity \\
\hline $\begin{array}{l}\text { Singh et al. [6], } \\
\text { 2010, Australia }\end{array}$ & $\begin{array}{l}41 \text { videos (10 celiac } \\
\text { and } 31 \text { normal) }\end{array}$ & $93.3 \%$ & $97.8 \%$ \\
\hline $\begin{array}{l}\text { De Luca et al. [10], } \\
\text { 2013, Italy }\end{array}$ & $\begin{array}{l}44 \text { patients with } \\
\text { suspected celiac } \\
\text { disease }\end{array}$ & $100 \%$ & $93 \%$ \\
\hline $\begin{array}{c}\text { Dutta et al. [7] } \\
\text { 2014, India }\end{array}$ & $\begin{array}{l}100 \text { patients with } \\
\text { suspected } \\
\text { malabsorption }\end{array}$ & $87.5 \%$ & $95.2 \%$ \\
\hline $\begin{array}{l}\text { Goswami et al. [9] } \\
\text { 2014, India }\end{array}$ & $\begin{array}{l}105 \text { patients with } \\
\text { suspected } \\
\text { malabsorption }\end{array}$ & $95 \%$ & $90.2 \%$ \\
\hline
\end{tabular}

need to be balanced against the potential usefulness of this procedure. The current level of evidence is still in its early stages and more data is required before recommending widespread clinical usage. Overall, magnification NBI endoscopy appears to be a promising tool in assessing duodenal villous morphology and is likely to play a role as a diagnostic aid in evaluation of patients with suspected malabsorption.

\section{References}

1. Larghi A, Lecca PG, Costamagna G. High-resolution narrow band imaging endoscopy. Gut. 2008;57:976-86.

2. East JE, Tan EK, Bergman JJ, Saunders BP, Tekkis PP. Metaanalysis: narrow band imaging for lesion characterization in the colon, oesophagus, duodenal ampulla and lung. Aliment Pharmacol Ther. 2008;28:854-67.

3. Song J, Zhang J, Wang J, et al. Meta-analysis of the effects of endoscopy with narrow band imaging in detecting dysplasia in Barrett's esophagus. Dis Esophagus. 2014. doi:10.1111/dote.12222.

4. Nagorni A, Bjelakovic G, Petrovic B. Narrow band imaging versus conventional white light colonoscopy for the detection of colorectal polyps. Cochrane Database Syst Rev. 2012;1, CD008361.
5. Shahid MW, Buchner A, Gomez V, et al. Diagnostic accuracy of probe-based confocal laser endomicroscopy and narrow band imaging in detection of dysplasia in duodenal polyps. J Clin Gastroenterol. 2012;46:382-9.

6. Singh R, Nind G, Tucker G, et al. Narrow-band imaging in the evaluation of villous morphology: a feasibility study assessing a simplified classification and observer agreement. Endoscopy. 2010;42:889-94.

7. Dutta AK, Sajith KG, Shah G, et al. Duodenal villous morphology assessed using magnification narrow band imaging correlates well with histology in patients with suspected malabsorption syndrome. Dig Endosc. 2014. doi:10.1111/den.12285.

8. Uchiyama Y, Imazu $\mathrm{H}$, Kakutani $\mathrm{H}$, et al. New approach to diagnosing ampullary tumors by magnifying endoscopy combined with a narrow-band imaging system. J Gastroenterol. 2006;41:483-90.

9. Goswami A, Dadhich S, Bhargava N. Use of narrow band imaging in assessing duodenal villous atrophy. Indian J Gastroenterol. 2014; 33: doi:10.1007/s12664-014-0489-4.

10. De Luca L, Ricciardiello L, Rocchi MB, et al. Narrow band imaging with magnification endoscopy for celiac disease: results from a prospective, single-center study. Diagn Ther Endosc. 2013;2013: 580526.

11. Banerjee R, Reddy DN. High-resolution narrow-band imaging can identify patchy atrophy in celiac disease: targeted biopsy can increase diagnostic yield. Gastrointest Endosc. 2009;69:984-5. 